\title{
Aproximación estilística a la obra de Lola Massieu
}

\author{
ISABEL DE LA CUÉTARA SAN LUIS * \\ Stylisc approach to Lola Massieu's work
}

\begin{abstract}
RESUMEN:
A lo largo de este artículo veremos el desarrollo estilístico de Lola Massieu, pintora grancanaria que desarrolla su obra en la segunda mitad del s. XX, desde sus inicios en los años 40, cuando se inicia en la pintura al óleo cultivando los géneros tradicionales de la pintura como el bodegón y el retrato con lenguajes que pivotan entre el impresionismo y expresionismo, y cómo poco a poco, a partir de la síntesis de las formas de los objetos, desarrollará composiciones informalistas en la década de los años sesenta y setenta, para llegar finalmente a la plena libertad creadora que guiará sus instintos y anhelos de comunicación, tras décadas de experiencia e investigación pictórica.
\end{abstract}

\section{PALABRAS CLAVE}

Lola Massieu, Pintura informalista, islas Canarias, Segunda mitad s.XX

\begin{abstract}
:
This article is focused on Lola Massieu's paintings and her works stylistic evolution. Born in Gran Canaria she started her career painting traditional themes as still life or portrait in oils fluctuating between impressionist and expressionist languages. This was in the forties but soon, little by little, her works entered a quest to summarize objects forms which led her to informal compositions in the sixties and seventies. Never deserting her passion to look at new ways of painting, after decades of experience, she achieved a full creative freedom to lead her instincts and yearnings for communication.
\end{abstract}

\section{KEYWORDS}

Lola Massieu, Informalism paiting, Canary island, Second Half of the Twentieth Century

\section{LOLA MASSIEU (1921- 2007)}

Lola Massieu nace en la isla de Gran Canaria y desarrolla su obra en la segunda mitad del s. XX, su adscripción al informalismo, coincide con el momento de apogeo de este movimiento en Canarias, en los primeros sesenta del pasado siglo XX, «cuando se incorporan a este movimiento Pedro González y Lola Massieu

* Licenciada en Historia del Arte; Profesora tutora de la UNED Centro Asociado de Tenerife. isabeldelacuetara@la-laguna.uned.es 
como figuras más destacadas» (DE LA NUEZ, 1995, p. 361), a partir de estas fechas Massieu no abandonará la abstracción donde se encuentra a gusto y consigue un estilo personal que considera apropiado para expresar tanto su universo personal como su postura ante el mundo y la sociedad en la que vive.

Sobre Lola Massieu, a pesar de estar considerada en el archipiélago como uno de los mejores ejemplos del informalismo en Canarias, y que «el conjunto de su obra marca importantes hitos en la Historia del Arte en Canarias» (ALMEIDA, 2010, p.13) encontramos apenas una monografía sobre esta autora editada en 1995 y escrita por Orlando Britto Jinorio dentro de la colección Artistas Canarios, y algunas menciones en otras obras de carácter general del Arte en Canarias como «La abstracción en Canarias" de José Luis de la Nuez Santana. En la bibliografía sobre el arte español del s. XX suele aparecer mencionada como una de las fundadoras del grupo Espacio (CALVO SERRALLER, 1985: p. 473; CALVO SERRALLER,1991: p. 215 ) por lo que hay que acudir a otras fuentes para su estudio en profundidad, como son los catálogos de las numerosas exposiciones en las que participó, los artículos publicados en prensa y revistas especializadas, y fundamentalmente su obra.

Lola Massieu es una artista por vocación, cuya fuerza expresiva emanará de su propia condición de mujer y de una personalidad sensible al arte de su época, inquieta y experimentadora, que desarrolla un universo plástico personal y original, que intentaremos desglosar a lo largo se este pequeño trabajo de introducción a su obra.

Tras sus primeros años de aprendizaje y búsqueda de un lenguaje propio, se introducirá de lleno en la estética informalista jugando con las posibilidades expresivas de la materia que le llevará a introducir en sus cuadros nuevos materiales como betunes y alquitranes. Poco a poco irá pasando de unas construcciones ortogonales de composiciones cerradas, a una pintura más gestual, en la que la expresividad irá manando del propio gesto de pintar, a través de formas más expresivas que se desarollan en composiciones más abiertas. Siempre inquieta, Lola Massieu volverá a introducir elementos figurativos en sus obras como una evolución natural de su pintura, en la que la búsqueda de nuevos medios de comunicación le lleva a ir introduciendo dichos elementos figurativos en aras de una comunicación más directa con el público.

Caracterizará toda su obra un afán experimentador que le lleva primero a introducir betunes y alquitranes en su obra, o más adelante el oro, también se atreverá con esmaltes y tapices, géneros de carácter tradicional y artesanal, utilizando todos los lenguajes a su alcance siempre al servicio de su expresividad.

\section{PRIMEROS AÑOS DE APRENDIZAJE:}

Lola Massieu nace en Las Palmas de Gran Canaria el 10 de marzo de 1921 en el seno de una familia acomodada de la burguesía de la isla que cuenta entre sus 
componentes con dos personajes dedicados a la pintura con éxito dentro de las corrientes en boga. Su tío abuelo D. Nicolás Massieu y Falcón pintor de la segunda mitad del S. XIX, que posee una gran técnica pictórica de tradición clásica que desarrolla en pinturas de género paisajista o costumbrista en auge, y su tío Nicolás Massieu Matos, quien después de sus años de aprendizaje con su tío viaja a Inglaterra, Italia y París donde conoce el impresionismo de primera mano, posteriormente de vuelta a la isla, adaptó su trazo y su técnica de espátula empastada a los paisajes que pinta de Gran Canaria de factura impresionista con los que tuvo un notable éxito en el ámbito isleño.

Lola Massieu inicia su aprendizaje en el taller de su tío Nicolás Massieu y Matos en 1932, donde acude durante unos seis años a aprender dibujo haciendo numerosos ejercicios de encaje del natural bajo la disciplina impuesta por su tío, que aún no le dejaba experimentar con el color. Tras esos años de tediosos ejercicios y cansada de encajar y dibujar, su personalidad artística pugna por salir y se impacienta por iniciarse en el mundo del color, en el que intuye la fuerza liberadora que anhela, al ver a su tío y maestro mezclar los colores en sus composiciones impresionistas. Esta impaciencia y su fuerte personalidad le lleva a abandonar las visitas al taller de su tío para comprar sus primeros óleos, con los que comienza a pintar sus primeros estudios de naturalezas muertas, retratos y paisajes. Se lanzará a mezclar colores y a aplicarlos como había visto hacer a su tío en las innumerables horas que pasaba en su taller dibujando, iniciando así la búsqueda y definición de su estilo personal durante las dos décadas siguientes con un interés experimentador y autodidacta que no abandonará y le caracterizará durante el resto de su carrera.

\section{BÚSQUEDA Y DEFINICIÓN DE UN ESTILO DURANTE LAS DÉCADAS $D E 1940$ Y 50}

Durante la década de 1940, el panorama artístico y cultural en Canarias, igual que ocurre a nivel nacional, se caracteriza por la desaparición de los proyectos más vanguardistas como la Gaceta de Arte, o con suerte, la pérdida de fuerza de otros como la Escuela Luján Pérez, mientras prolifera y se apoya desde ámbitos oficiales una pintura academicista de retratos y paisajes bucólicos. Además se encarcelan a algunos miembros de la escuela Luján Pérez, como Felo Monzón, lo que provoca una ruptura de la investigación pictórica y estética.

En este ambiente las primeras obras de iniciación al color de Lola Massieu, participarán de los géneros tradicionales de la pintura, realizando retratos, paisajes y bodegones, que abordará como una experiencia absolutamente personal y trabajando prácticamente aislada en su casa en La Angostura, partiendo de parámetros de experimentación y liberación, y su necesidad de expresarse a través de la pintura, en la que su condición de mujer, madre y ama de casa hace que el acto de pintar suponga para ella un acto de liberación. 


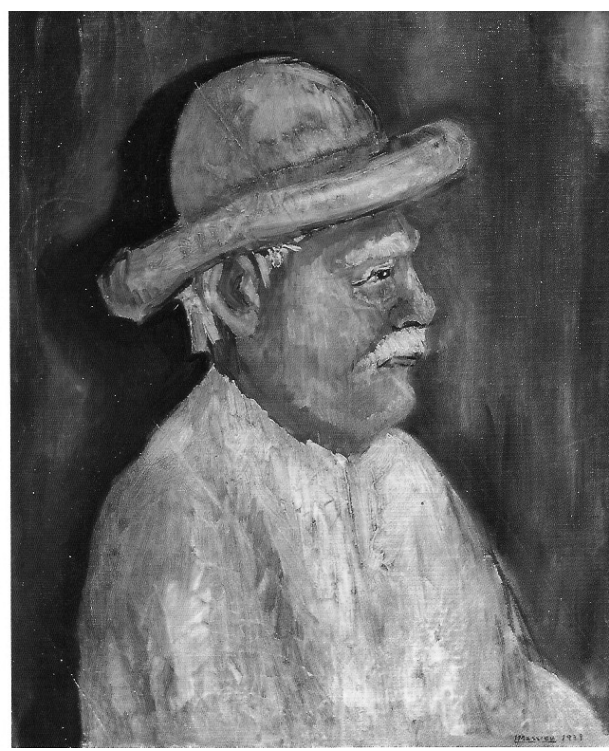

Fig. 1 Retrato de Juan Cerpa, 1939, 50 × $60 \mathrm{~cm}$. Óleo sobre lienzo

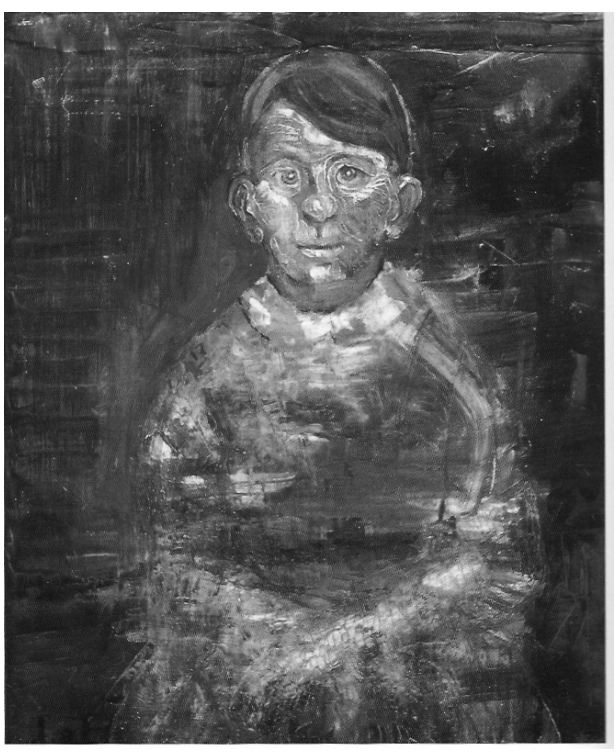

Fig. 2. Niña del Barco, $1939-40$ 59 x $72 \mathrm{~cm}$. Óleo sobre lienzo

Encontramos en sus retratos iniciales una doble vertiente: una de corte impresionista, de tono amable, en la que el color y la pincelada suelta definen la obra, compuesta por gruesos empastes donde el color se erige en forma y dibujo desde soluciones formales impresionistas. La otra vertiente que cultiva en estos primeros años, destaca por una fuerte carga dramática de carácter expresionista, con la que inicia su búsqueda de transmisión de sentimientos y mensajes con carga emotiva, dando prioridad a la expresión subjetiva que la acompañará el resto de su producción.

En los bodegones y jarrones con flores que pinta en estas décadas se puede observar una evolución hacia la s de formas. Desde bodegones de composición tradicional en los que el espacio y la profundidad perspectívicas pierden interés en favor del color y la luz como elementos moduladores de los volúmenes de los objetos, hasta aquellos en los que los objetos se representan con formas cada vez más sintéticas. Emplea un tratamiento de volúmenes a base de gruesos empastes y raspados de color en los que la luz va a ser el elemento clave de la estructura compositiva, de forma que su proceso de definición y síntesis se va forjando sobre estructuras de luz y color.

Asistimos a un proceso de conformación de un estilo propio, en el que va desarrollando una geometrización de la realidad a partir del tratamiento de los volúmenes de forma cada vez más sintética, que poco a poco van perdiendo los puntos de contacto con el objeto real para terminar convirtiéndose en rectángulos de 


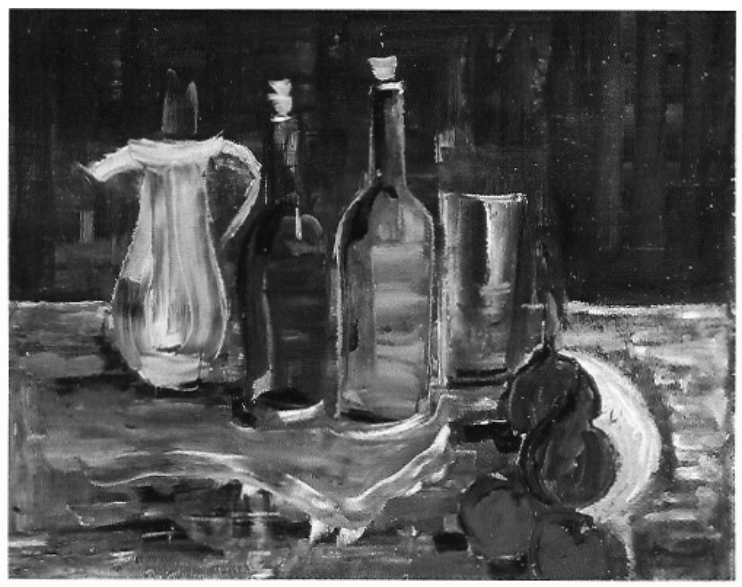

Fig. 3. Bodegón, h. 1947 $59,5 \times 72,5 \mathrm{~cm}$. Óleo sobre lienzo

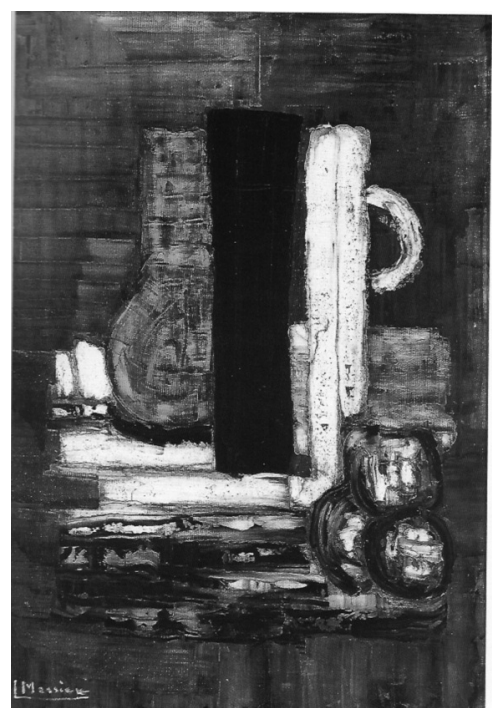

Fig. 4. Bodegón, 1950

$72 \times 50 \mathrm{~cm}$. Óleo sobre lienzo

color que sugieren una jarra, un vaso, o simples círculos a modo de frutas.Con esta obra construida sobre volúmenes cada vez más sintéticos Lola Massieu inicia el camino hacia soluciones abstractas sobre estructuras de volumen y color, que deja entrever soluciones formales compositivas originales, con un tratamiento del color y la materia, que le van acercando al mundo de la abstracción.

El uso de tierras y ocres que predomina en su obra, se ha querido relacionar con los colores predominantes en los paisajes de Gran Canaria, su isla natal en la que abundan los tonos terrosos del interior, junto a los ocres y amarillos de las playas, en palabras de de la Nuez Santana «las texturas y el colorido de los materiales de las obras de Massieu, Monzón y Dámaso hacen referencia expresa al medio insular.» (DE LA NUEZ, 1995: p. 362).

En el ámbito insular comienza a operarse un cambio en el panorama artístico con una leve recuperación, y a principios de los años cincuenta aparecerán grupos de artistas como el grupo LADAC (Los Arqueros del Arte Contemporáneo) que surge en Gran Canaria en 1951 (DE LA NUEZ, 1985; CARREÑO, 1990). Este grupo participa del espíritu del barcelonés «Dau al Set», que llega a las islas a través de Juan Ismael, quien estuvo en Barcelona durante 1949. Aunque de vida muy corta, las actividades desarrolladas por LADAC dinamizan el ambiente cultural de la isla, sobretodo con conferencias y exposiciones de arte contemporáneo que suscitarán debates en la prensa escrita acerca de la idoneidad de los nuevos lenguajes desarrollados por los integrantes del grupo. 
Otro foco dinamizador será la Escuela Luján Pérez, y uno de sus más prolíficos profesores y posteriormente director, Felo Monzón, firme defensor del arte «nuevo» como se desprende del título de algunas de sus conferencias impartidas en la escuela Luján Perez, como la que dio en 1948 bajo el título «Elogio del arte vivo», o la de 1949: «La escuela Luján Perez y el arte nuevo». Es bastante probable que Lola Massieu estaría al tanto, como espectadora de las nuevas corrientes y debates que se estaban produciendo a su alrededor, mientras ella estaba en La Angostura creando inmersa en la búsqueda de su propio lenguaje.

En estos años comienza a experimentar con la materia y realiza sus primeras incursiones en el mundo de los alquitranes, como ella misma relata en alguna ocasión, tomaba los alquitranes de los obreros que trabajaban en su casa para introducirlos en sus lienzos (BRITTO, 1995, p. 70). Rápidamente dominará las posibilidades expresivas de este material que a través veladuras y raspados darán a su obra una personalidad propia que desarrollará en las décadas posteriores desde una estética informalista.

A finales de la década de los años cincuenta comienza a visitar la Escuela Lujan Pérez, donde conoce a numerosos artistas que se congregaban allí e inicia su amistad con Felo Monzón, artista y teórico de las islas que ejerció de profesor y director en la Escuela. Durante estas visitas Lola Massieu puede confrontar su obra con la de otros artistas de la época, superando el aislamiento inicial en el que había desarrollado sus primeros lienzos en su casa de La Angostura como una actividad personal y liberadora.

Toda la actividad descrita la realiza en su casa en La Angustura, como ya se ha comentado, de manera personal y prácticamente aislada, hasta que a finales de los años cincuenta, apoyada por sus amigos decide mostrar al público su obra, y realiza su primera exposición en 1958 en el Museo Canario en Las Palmas de Gran Canaria, donde colgará unos ochenta lienzos de sus obras más figurativas, convencida de que éstas tendrían mayor aceptación en el público isleño, un año más tarde expondrá en el Casino de Tenerife, a raíz de esta exposición la artista conocerá a Eduardo Westerdahl, quien rápidamente se convertirá en defensor de la artista valorando muy positivamente el camino iniciado por ella hacia la abstracción.

La amistad con Felo Monzón, pintor erudito y crítico, férreo defensor en las islas de la «nueva pintura» frente a la académica, fue realmente provechosa para Lola Massieu, él fue quién desde el principio la apoyó en la línea que había iniciado en la década anterior, y la ayudó a situar intelectualmente su obra desde una nueva forma de entender los procesos de creación artística, entrando de lleno en el mundo de la abstracción.

Por otro lado Felo Monzón mantenía una estrecha relación con artistas canarios que se habían desplazado fuera de las islas durante la década de los 50 como Manolo Millares, Martín Chirino, o César Manrique que le mantenían al día 
de las nuevas corrientes mandando catálogos y noticias de las últimas exposiciones realizadas, de esta forma conseguían estar al corriente de los nuevos movimientos y estilos en el archipiélago a pesar del aislamiento geográfico.

El papel jugado por Millares en la internacionalización del Arte Abstracto participando en numerosas exposiciones como la «Exposición Internacional de Arte Abstracto" en 1953, la muestra "Otro Arte» de 1957, que tuvo "una influencia decisiva en la asimilación e implantación del informalismo en España» (TUSELL, 2003, p. 226); o la participación en muestras internacionales en el MOMA o en el Guggenheim de Nueva York, entre otras atestiguan su febril actividad durante estos años a la vanguardia de las creaciones artísticas españolas de arte abstracto y está ampliamente estudiada. Por otro lado la correspondencia entre Millares y Monzón se puede atestiguar en el capítulo «La correspondencia Monzón-Millares: radiografía de una época», del catálogo de la exposición retrospectiva de Felo Monzón en el CAAM de 1999 (ver bibliografía), de esta forma se puede entender esa superación en las islas del aislamiento y la modernidad de las propuestas de Monzón o Massieu, entre otros artistas canarios.

\section{INFORMALISMO EN LOLA MASSIEU DURANTE LA DÉCADA DE 1960}

En los años sesenta en Canarias con el inicio del desarrollo del turismo de masas en las islas, comienzan a desarrollarse nuevas condiciones económicas que propician la aparición de un incipiente mercado del arte y se abren nuevos espacios expositivos donde colgar las obras del «nuevo arte», que se unirán a las ya mencionadas de la Escuela Luján Pérez y el Museo Canario en el caso de Las Palmas de Gran Canaria.

Continuará la reflexión tímidamente iniciada en los años anteriores sobre la validez del arte abstracto como vehículo de expresión, entre otros, Felo Monzón dará dos significativas conferencias en 1959 tituladas «Arte nuevo y realidad» y «Arte abstracto actual», y dos años después una serie de jóvenes creadores se aglutinaron en torno a él formando el grupo Espacio, en el que se integraron Lola Massieu, Rafaely Bethenchourt, Pino Ojeda entre otros, favoreciendo la consolidación de los lenguajes informalistas y no figurativos como una verdadera alternativa plástica en Canarias. Para el catedrático Fernando Castro Borrego, durante estos años produjeron su mejor obra artistas como Pedro González, Manolo Casanova, Maribel Nazco, José Luis Fajardo, Lola Massieu o Pepe Dámaso (CASTRO BORREGO, 1992, p. 21).

Tras las décadas de los años cuarenta y cincuenta que hemos descrito aquí como de definición estilística, asistimos en los años sesenta a la emancipación definitiva de la obra abstracta de Lola Massieu acuciada por la necesidad de cambiar definitivamente el rumbo de su obra tomando el camino de la abstrac- 
ción, en lo que la propia artista considera el «paso al mundo de la imaginación» en una entrevista publicada en Diario de Las Palmas en 1961*, ella misma lo describe:

- ¿Qué sensación experimentó al primer contacto con lo abstracto?

- Dejar de copiar para pasar al mundo de la imaginación que es donde me encuentro a gusto. En lo figurativo lo más que puede hacer el pintor es idealizar los objetos dados, hacer una casi abstracción de la realidad interpretando a su modo el objeto que pinta. Pero en la abstracción no hay que atenerse a formas.

Su obra alcanza ahora altas cotas de madurez y personalidad, hasta constituir una de las principales manifestaciones del informalismo en Canarias. Su seña de identidad será en estos años una pintura sobria que desarrolla una particular forma de construir el espacio, y cuyos elementos definitorios se desarrollarán a través de luz, materia y estructura compositiva.

Sus obras se construyen sobre estructuras geométricas que organizan el espacio y dan pie a una rica libertad expresiva a través de composiciones basadas en pesadas franjas o estructuras verticales u horizontales que contrasta con otras veladas, que llevan a Eduardo Westerdahl a compararla con Nicolás de Stael o Mark Rothko, como veremos más adelante.

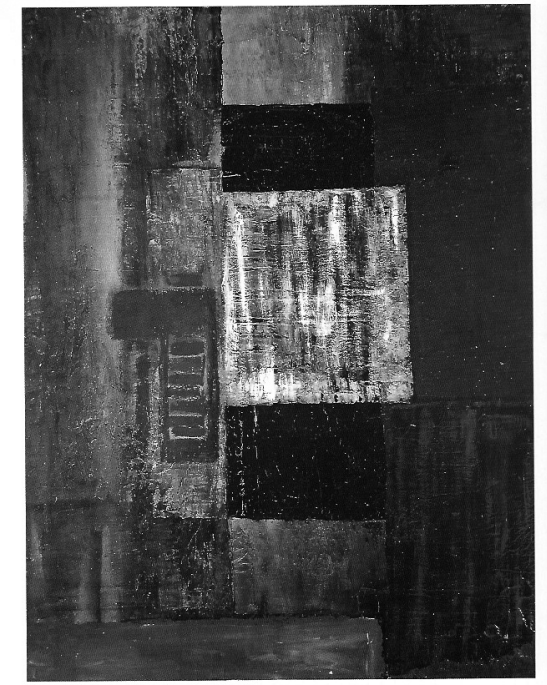

Fig. 5. Sin título, $1957-58$

73 x $60 \mathrm{~cm}$. Técnica mixta sobre lienzo

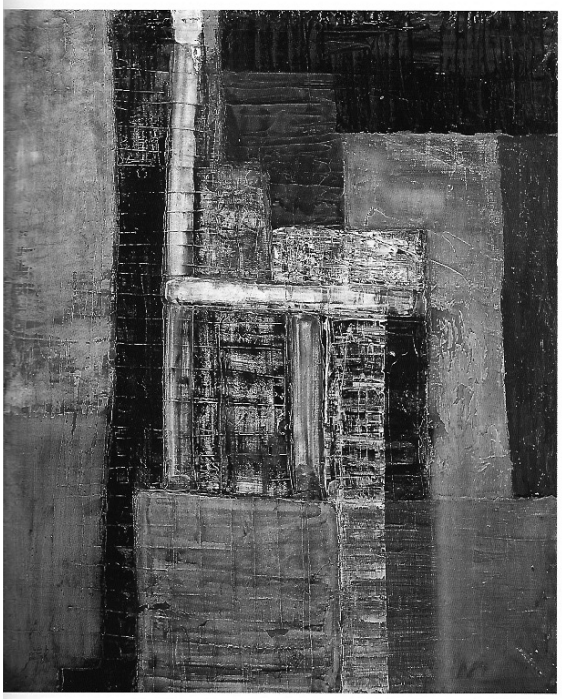

Fig. 6. Sin título, $1959-60$

$73 \times 60 \mathrm{~cm}$. Técnica mixta sobre lienzo

* GARCIA JIMENEZ; L: «Lolita Massieu: De lo figurativo a lo abstracto», Diario de Las Palmas, Las Palmas de Gran Canaria. 08/ 04/1961. 
El espacio y su articulación en el lienzo será una de las mayores preocupaciones de Lola Massieu en esta época, lo que le lleva a participar, como ya se ha comentado, en la fundación del Grupo Espacio que se constituye en 1961 en Las Palmas de Gran Canaria junto a Felo Monzón, teórico y redactor del manifiesto, y otros artistas. La base teórica del grupo será la defensa del espacio como eje de la articulación del lenguaje pictórico, la lectura del manifiesto firmado por los artistas es muy interesante para comprender los deseos de este grupo, aquí reseñaremos cuatro frases que consideramos importante reproducir:

«Sólo se salva la vigencia inalterable, abierta, del espacio como valor plástico permanente».

«En la profunda dimensión de la espacialidad encontramos, lo auténtico y puro el arte de ayer y hoy».

«El espacio y sus relaciones llegan a su plena confirmación con la estética nofigurativa»

«La nueva espacialidad opera con el misterio de la materia viva» $†$

El papel del espacio pictórico para los componentes del grupo es el único valor plástico válido desde los inicios de la pintura, que se validará con la obra no-figurativa en la que las formas naturales pierden valor a favor de la espacialidad, concepto que además interactúa con la materia del cuadro.

Enlazando con la pintura «espacialista» informal, que pretendía lograr una noción de espacio pictórico muy distinto al tradicional, cuyo mayor exponente será Rothko, (CIRLOT, 1990: p. 10). O cómo la define Gillo Dorfles: «Una nueva espacialidad que a menudo trataba de ser algo distinto y más importante que la atmosférico-impresionista y que la abstracto-constructivista; que pretendían por tanto la construcción de un espacio artístico diferenciado con respecto al ambiente, pero al mismo tiempo enteramente abstracto y no referible a ninguna realidad" (DORFLES: 1976: p. 87).

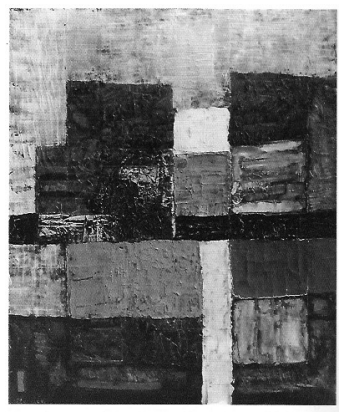

Fig. 7. Pintura 5, h.1961. $65 \times 54 \mathrm{~cm}$. Técnica mixta sobre lienzo

† «Manifiesto del grupo Espacio», 1961, en BRITTO, O: 1995, pp. 180-181 
«Se trata de aquellas obras cuyo sentido esencial es transformar de modo absoluto, la concepción tradicional del espacio, aunque dicha transformación no se logra a través de cortes ni perforaciones, sino simplemente por medio de capas pictóricas sobre grandes lienzos, utilizando dos o tres colores a lo sumo, como en el caso de Rothko. El color, con sus diversas gradaciones, se convierte aquí en el factor modificador del espacio» (CIRLOT, 1983: p. 35)

La obra de Lola Massieu anuncia ahora la ruptura de la materia con la estructura del soporte y se abre paso una mayor libertad gestual que suaviza sus composiciones anteriores de estructuras más rígidas, de forma que el rigor estructural va a ir poco a poco desapareciendo a favor de una gestualidad más temperamental, acorde con su propia naturaleza.

En 1962 expondrá fuera del ámbito insular junto a Felo Monzón en el Museo de Arte Contemporáneo de Barcelona, la obra expuesta en esta muestra no pudo volver a las islas por una serie se problemas administrativos en la aduana, y se encuentra actualmente en el Muesu Nacional d`Art de Catalunya, en la Casa Mueso Balaguer, este tipo de problemas administrativos de los artistas isleños para sacar su obra fuera de las islas queda muy bien reflejado en el artículo «Crítica y vanguardia en el arte español de los cincuenta: la correspondencia entre Gaya Nuño y Manolo Millares" de José Luis de la Nuez Santana que extrae de una de las cartas personales enviadas por Millares a Gaya Nuño "Mi exposición en 'Clan', por las pocas noticias que me han llegado, no ha podido hacerse debido a la detención de mi obra en la aduana de Barajas; jun desastre!” (DE LA NUEZ: 2011, p. 123).

En el catálogo de la exposición a cargo de Eduardo Westedahl, el crítico escribirá sobre la obra de la artista‡:

«La pintura de Lola Massieu tiene por firme base el rigor de las estructuras. Sobre estos planos de color tan directos y apasionados las estructuras ceden su puesto a una libertad expresiva fresca y jugosa como un acto poético. Esta simbiosis platónico-dionisiaca nos da el equilibrio de una obra de arte dentro de la gran familia de los Stael, Poliakoff y Rothko...».

«Su camino ha sido rápido y responde a su natural vehemencia. No hizo el recorrido por escuelas o movimientos artísticos de prueba. Fue en principio directa a la materia, tratando el bodegón con una espectacular densidad, de forma brutal y desesperada...».

En ese mismo año de 1962, expondrá también en el en Spanishes Kulturnistitud in der residenz en Munich, también junto a Felo Monzón y Pedro González, Lola Massieu continuará en el camino iniciado de liberación de las estructuras a favor de una mayor libertad expresiva. En 1964 expondrá individualmente en la

‡ WESTERDAHL, texto para el Catálogo de la exposición de en el Museo de Arte Contemporáneo de Barcelona, 1962 en BRITTO, O: 1995. p. 171-172. 
sala del Prado del Ateneo de Madrid, donde presentará obras figurativas y abstractas.

Estas exposiciones fuera de las islas hacen pensar en un futuro prometedor y de reconocimiento para la artista, si bien esto no fue así, bien debido a las trabas administrativas, bien por decisión personal de Lola Massieu de no querer abandonar su isla natal por motivos familiares, hay que recordar que Lola Massieu tenía a su cargo una familia numerosa de ocho hijas, lo cierto es que hay que esperar hasta los años noventa para ver de nuevo la obra de Massieu fuera de las islas, en Sevilla o Madrid.

Durante esta época, independientemente del desarrollo informalista de su pintura y en consonancia con su faceta experimentalista, la pintora comienza a realizar una serie de esmaltes y tapices de carácter popular, en los que vuelve a introducir elementos naturalistas, como una vuelta a lo primario, a las raíces del arte, que además le proporcionaba una nueva fuente de experimentación con materiales y soportes. Esta línea de trabajo, sin embargo, no debe alejarnos de la trayectoria de Massieu, si no que se integra en otra más de sus facetas artísticas, su preocupación no sólo por lo más nuevo del arte, sino también una preocupación por las artes decorativas y la artesanía, más adelante abrirá incluso una escuela de artesanía.

Así pues, a finales de la década de los años sesenta encontramos una artista madura, que desarrolla una obra personalísima, que tras dominar las estructuras y el espacio dentro de una concepción ortogonal, se lanza a una pintura gestual, orgánica, en la que introduce nuevos elementos de liberación de sus rígidas estructuras anteriores, además se produce un reconocimiento a nivel crítico y consigue exponer fuera del ámbito isleño.

\section{APERTURA DE NUEVAS VÍAS DE COMUNICACIÓN EN LA DÉCADA DE 1970}

En los años setenta asistiremos en Canarias a una renovación generacional de artistas y críticos, partícipes del sueño de una sociedad democrática y plural, que se erigirán en la vanguardia cultural de las islas, será la llamada «Generación de los 70", que se aglutinarán en torno a la Sala Conca de La Laguna, un espacio expositivo que a parte de la función expositiva, será lugar de encuentro de la nueva generación de creadores, unos años más tarde se abrirá en Las Palmas la sala Conca 2. En este ambiente de renovación, aparecen nuevas revistas culturales y secciones culturales en la prensa local que dieron cobertura a las necesidades intelectuales del momento y a todas las iniciativas y actividades que se estaban dando en las islas.

En 1976 hay que señalar como hecho histórico en la concienciación de un arte canario, la redacción del Manifiesto de El Hierro, que firman setenta inte- 
lectuales y artistas, en el que se reclamaba la legitimidad de un origen autóctono de la cultura canaria, aunque sin negar los lazos con los pueblos de España, África y América.

La obra de Lola Massieu en esta década se consolida y continúa con la búsqueda de nuevos caminos de comunicación acentuándose el carácter expresivo de su pintura. Abandona la rigidez de las estructuras ortogonales que había explotado en la década anterior para sumergirse en una abstracción más abierta, más blanda en la que el espacio se define con texturas en forma de extrañas formas orgánicas que recuerdan tendones o músculos. Técnicamente se apoya en la decalcomanía, y en su recurso matérico a base de resinas y óleos.

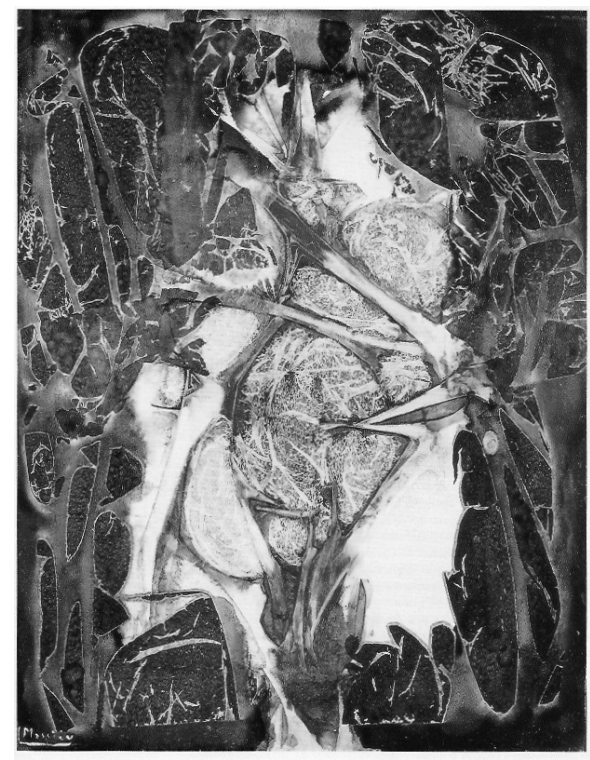

Fig. 8. Sin título, 1970

$100 \times 100 \mathrm{~cm}$. Técnica mixta sobre

Esta técnica que define el espacio con texturas en forma de extraños esqueletos acentúa la sensación de desasosiego y comienza a diseñar un imaginario personal que nace de la suma de sus sensaciones y vivencias, dando rienda suelta a su personalidad vehemente, que siempre le lleva a ir un poco más allá en sus experimentaciones y nunca conformarse con un pequeño éxito o una buena crítica. Como una natural evolución de esas formas orgánicas que ha ido introduciendo en sus obras, se opera un nuevo cambio en su pintura, elementos y formas naturales comienzan a visualizarse en su obra buscando alcanzar nuevas formas de representación y nuevos horizontes de comunicación, así aparece el ojo, como un elemento de comunicación con el espectador, que se siente observado desde estructuras informes. 


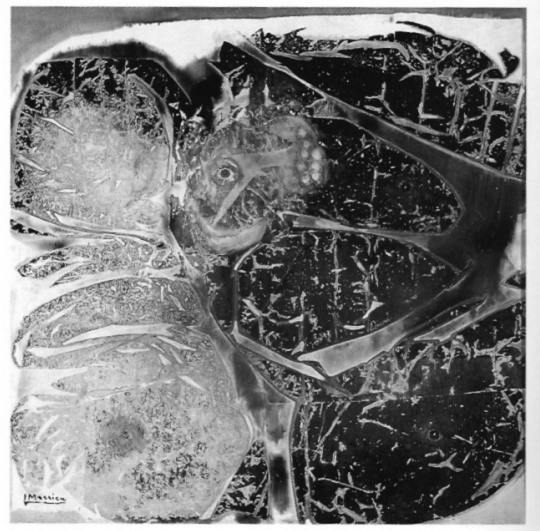

Fig. 9: La mujer quemada, 1974 100 x $100 \mathrm{~cm}$. Técnica mixta sobre tabla

El Grupo Espacio goza ahora de un segundo momento de eclosión, que ahora y en consonancia con el momento que se vive, ya no se centra únicamente en el problema del «espacio» desde una óptica exclusivamente artística o estética, sino que busca acercar el arte a la población, dentro del proceso de democratización a todos los niveles que se estaba viviendo en España.

Es significativo el cambio de tono en la declaración de principios del Grupo que redactan en el catálogo para la exposición colectiva en la Sala Cairasco en 1978: El Grupo «Considera que el producto artístico no es de minorías. Arte hay en todo: en la vida intelectual y científica, en la tarea proletaria; en el arte pensado por un adulto y en el juego vital del niño, que aporta la alegría naïf y la pureza plástica»§. De las actividades del grupo en esta época destaca la exposición de murales en la calle en 1978, dentro de los actos conmemorativos del quinto centenario de la fundación de Las Palmas de Gran Canaria, que pretendía acercar el arte a la gente, ubicando obras de artistas señeros en el lugar público por excelencia, la calle.

Ya hemos visto cómo la fuerte personalidad de Lola Massieu, siempre atenta al tiempo en el que vive, le anima a emprender otras actividades ajenas al ejercicio de la pintura en sí aunque no al mundo de la cultura en el sentido más amplio, como vimos se introdujo en el ámbito de las artes decorativas y artesanía con la realización de tapices y esmaltes. Ahora, a principios de la década abrirá una academia de artesanía dónde se impartirán clases de cerámica, esmalte, estaño, ebanistería, etc, como respuesta a una preocupación por la pérdida de las tradiciones populares artesanales.

§ AAVV: «Catálogo Grupo Espacio. Murales en la calle. Exposición colectiva». Ed. Obra cultural Caja Insular de ahorros de Gran Canaria. Las Palmas de Gran Canaria. 1978. 


\section{6.-ÚLTIMAS DÉCADAS DE TOTAL LIBERTAD CREADORA DESDE LA EXPERIENCIA.}

A partir de los ochenta con el nacimiento de las comunidades autonómicas, son las instituciones las que pretenden dinamizar el panorama cultural, quedando los procesos de expansión cultural bajo la tutela de dichos organismos autonómicos cuya función principal será, y aún se mantiene, la realización de programas de proyectos y exposiciones que intentan mostrar a la ciudadanía los aspectos más sobresalientes de la cultura canaria. Se abren nuevos centros de Arte auspiciados por los gobiernos autonómicos o insulares, como el CAAM en Las Palmas de Gran Canaria, que abre sus puertas el 4 de diciembre de 1989.

En las últimas décadas la obra de Lola Massieu, ya plenamente madura y segura se nos presenta ahora ligera, rápida y gestual, extrae la fuerza expresiva de la materia, con sus habituales betunes y alquitranes y el hábil uso de las veladuras, decalcomanías y «drippings», que domina tras años de experiencia e investigación. Sus composiciones, a veces retoman esas estructuras ortogonales con las que inició su camino hacia la abstracción, aunque ya no son tan rígidas, pues esa rigidez ortogonal se ve rota por los distintos efectos que consigue Lola Massieu con los recursos técnicos que domina antes mencionados.

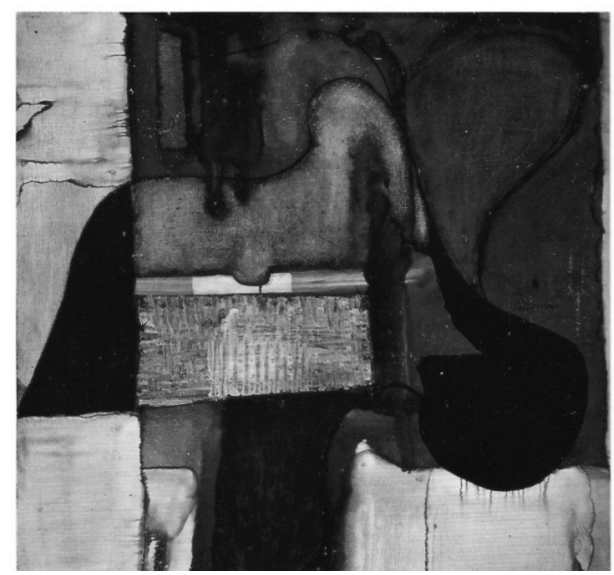

Fig. 10. Sin título, 1980

$86,5 \times 92 \mathrm{~cm}$. Técnica mixta sobre tabla

El Informalismo, si aún se le puede llamar así, pues hemos visto cómo ha introducido elementos formales, es ya más una cuestión de actitud, de libertad creadora, en Lola Massieu encontramos algo de los tres «subgrupos» en los que algunos historiadores dividen el movimiento (CIRLOT, 1985)

Hay pintura matérica en su afán de búsqueda de nuevos materiales, hay pintura espacial en una concepción del espacio en sí mismo, en el que cada cuadro crea su propio espacio recorrido por extrañas formas o informas, y poco a poco ha 
ido introduciendo la gestualidad, en la que el brazo y la mano toman las riendas sobre las estructuras ortogonales iniciales.

Carlos Gaviño, y Carlos Díaz-Bertrana lo expresan en el catálogo de la exposición en la Casa Museo Colón en 1981: "Convencida por el informal, empapada por la ortodoxia y la certeza de una propuesta plena, toda su obra tiene un marcado matiz hedonista. Habiendo renunciado a la truculencia -adoptada por los potinformalistas- resume en la pervivencia los estertores de aquel movimiento y su indeterminación lingüística. (...) Alejada del modernismo y su frialdad intelectualizada continúa en el empeño de las viejas hazañas en las que la libertad era la única constancia y despliega en sus telas la memoria de la nueva pintura ocupando así, un espacio indispensable en la plástica canaria. "**

Aunque aprovecha todo lo aprendido durante todos estos años de dedicación a la pintura, Lola Massieu mantiene ese pulso que le lleva siempre a un continuo proceso de evolución y vuelve a experimentar con nuevos materiales, ahora introduce el oro en su obra dentro de un proceso de investigación sobre la espiritualidad y la magia del oro que se incorpora como un nuevo elemento en su obra.

El oro como símbolo y metáfora de la luz, de lo trascendente nos da una nueva lectura de la realidad desde claves espirituales y trascendentes, aunque parece chocar con la aparente secularidad de un lenguaje informalista, no figurativo, la artista sabe conjugar a la perfección desde su completa libertad e ironía, atreviéndose incluso con un género eminentemente religioso como el tríptico.

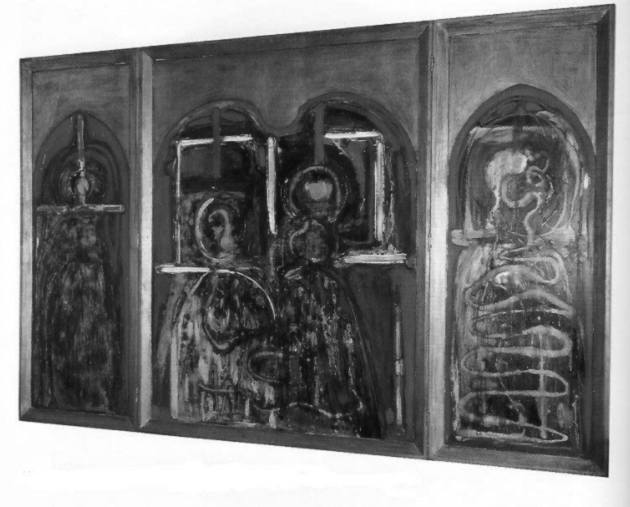

Fig. 11: Tríptico, $1980-81$

173 × $348 \mathrm{~cm}$. Técnica mixta sobre tabla

Lola Massieu como artista de pleno derecho en la plástica canaria crea ya desde una absoluta libertad de composición y de discurso, con gran dominio de la materia. En 1990 se le concede el Premio Canarias de las Bellas Artes e Interpreta-

** GAVIÑO, C y DIAZ BERTRANA, C Texto del catálogo de la exposición en la Casa Museo Colón en 1981, en BRITTO, O 1995. p. 178-179. 
ción, como un reconocimiento definitivo de su obra a nivel regional que debe ocupar un lugar predominante en la plástica del archipiélago. «El Premio le fue concedido por mayoría por un jurado, que presidido por el director del CAAM Martín Chirino, valoró su aportación al arte contemporáneo y su significación como pionera en la interpretación y desarrollo del arte canario en el siglo $X X_{\text {» }}{ }^{\dagger+}$.

A lo largo de su dilatada experiencia Lola Massieu ha ido ampliando la gama de colores que ahora maneja con total libertad y control en función del mensaje que encierra cada obra, aunque aún hay predominio de las tierras, también hay una mayor complejidad en su concepción y tratamiento del espacio. Realiza ahora sus series «Un mundo en descomposición»; «Recuerdos de mi niñez», o «Manzana podrida», que va ejecutando a lo largo de la década como respuesta a sus distintos estados de ánimo o a sus impulsos expresivos.

La producción final de la obra de Lola Massieu se concentra fundamentalmente en obra sobre papel, y sorprende cómo mantiene en su registro pictórico, una estructuración del espacio de composición muy cuidada que desarrolla una espacialidad diáfana.

Lola Massieu está considerada uno de los máximos exponentes del informalismo en Canarias, esto no deja de ser cierto, si bien tras el estudio detallado de toda su obra, queda patente que la producción pictórica de la artista que aquí nos ocupa va más allá. Fue ante todo una artista sincera consigo misma, con una concepción vital de la pintura en la que hallaba un mundo de libertad creadora. Si bien sus primeros pasos estuvieron condicionados por su condición de mujer y ama de casa que se libera a través de la pintura, poco a poco fue conquistando la técnica pictórica y haciéndose un hueco en el panorama artístico canario. Su natural curiosidad y vehemencia le llevó a mantener durante toda su vida un estilo propio que le fue llevando hacia nuevos desarrollos pictóricos, superando el informalismo inicial, siempre en busca de nuevas formas de expresión acordes con su espíritu y el de su época.

La falta de estudios monográficos publicados sobre Lola Massieu, deficiencia sobre la que ya en 1995 había llamado la atención en Orlando Britto Jinorio al publicar su monografía dentro de la colección «artistas canarios», aún no ha sido subsanada, aunque con este trabajo se trata de rectificar, intentando dar un impulso al reconocimiento no sólo de Lola Massieu, si no del arte en unas islas en una época en la que no era fácil dedicarse a la práctica artística y menos al «arte nuevo», en una sociedad eminentemente conservadora a la que sólo le interesaban cuadros de paisajes bucólicos de corte tradicional de las islas que no se planteaban nada más allá de lo estético. La superación de esta pintura tradicional en Canarias vino de la mano de algunos artistas valientes y obstinados como Lola Massieu y otros de su generación que con su empeño consiguieron integrar la pintura abs-

t† «Lola Massieu. Premio Canarias de Bellas Artes 1990» En Atlántica. Revista de las Artes no 0 octubre 1990 Ed. CAAM, Las Palmas de Gran Canaria. 
tracta no figurativa en el ámbito cultural de las islas con un afán internacionalista que pretendía superar el provincianismo en el que se había instalado la élite cultural.

\section{BIBLIOGRAFIA}

AAVV: “Catálogo Grupo Espacio. Murales en la calle. Exposición colectiva». Ed. Obra cultural Caja Insular de ahorros de Gran Canaria. Las Palmas de Gran Canaria. 1978

BRITTO, O: «Massieu», en Biblioteca de Artistas Canarios. Santa Cruz de Tenerife. Ed. Viceconsejería de Cultura del Gobierno de Canarias, 1995

BRITTO, O y ZAYA, A: Lola Massieu. Retrospectiva. Catálogo para la exposición. Ed. Tobapress, Madrid 1996.

CABREA ALMEIDA, P: Lola Massieu. Catálogo para la exposición. Ed. Fundación Mapfre Guanarteme, Las Palmas de Gran Canaria, 2010

CALVO SERRALLER: España, medio siglo de arte de vanguardia: 1939 - 1985; Ed. El Viso, Madrid, 1985.

CALVO SERRALLER: Enciclopedia del arte español del s. XX. Ed. Arco/lfema. Madrid, 1991.

CARREÑO CORBELLA, P: LADAC: el sueño de los arqueros, Ed. Viceconsejería de Cultura y Deportes, Las Palmas de Gran Canaria, 1990.

CASTRO BORREGO, F: El arte de los años 60 en Canarias, Catálogo para la exposición Ed. Caja General de Ahorros de Canarias, Tenerife, 1992.

CASTRO BORREGO, F: Lola Massieu. La persistencia de la pasión. Catálogo para la exposición Ed. Obra social de Caja Canarias. S/C de Tenerife, 2001

CASTRO MORALES, F y DE LA NUEZ SANTANA, J. L., «La correspondencia Monzón-Millares: radiografía de una época», en AA.VV., Felo Monzón. Retrospectiva, Las Palmas de G. Canaria, 1999, pp. 239-255.

CIRLOT, L: La pintura informal en Cataluña, 1951 1970. Ed. Anthropos Editorial del hombre, Barcelona, 1985.

CIRLOT, L: Las últimas tendencias pictóricas, Ed. VicensVives, Barcelona, 1990.

DE LA NUEZ, J. L: La abstracción pictórica en Canarias. Dinámica histórica y debate teórico (1930 1950). Las Palmas de Gran Canaria. Ed. Cabildo Insular de Gran Canaria. 1995

DE LA NUEZ SANTANA, J. L: “Crítica y vanguardia en el arte español de los cincuenta: la correspondencia entre Gaya Nuño y Manolo Millares» Archivo español de Arte, 334 (2011), pp. 107 - 124

DE LA NUEZ, J. L: «El grupo LADAC y la vanguardia artística grancanaria». Aguayro. Boletín informativo, oㅜ 160 (1985) pp. 1317

DORFLES, G: Ultimas tendencias del arte de hoy. Ed. Labor, Barcelona, 1976

FRANCO, O: Voces de Lola Massieu. Catálogo para la exposición. Islas Canarias. Ed. Viceconsejería de Cultura del Gobierno de Canarias, 2002

FRANCO, O: Diálogo a tres: el legado Massieu. Catálogo para la exposición. Ed. La caja de Canarias, Las Palmas de Gran Canaria, 2005

HERNANDEZ, J. S: «El grupo Nuestro Arte, impulsores del arte de vanguardia en la década de los sesenta». Tebeto: Anuario del Archivo Histórico Insular de Fuerteventura, oㅜ 10, (1997). pp. 283308 
HERRERO, P: Veinticinco años de Arte en Canarias (1961 - 1986). Ed. La Caja de Canarias, Las Palmas de Gran Canaria, 1987

RODRIGUEZ DORESTE, J: «La Escuela de Artes Decorativas de Luján Pérez. Algunas notas para su historia». Revista del Museo Canario, no 75, 76. (1960) pp. 139182

TUSELL, G: «La internacionalización del arte abstracto español: el intercambio de exposiciones con los Estados Unidos (1959 - 1964). Espacio, Tiempo y Forma, Serie VII, H. del Art. № 16, (2003), pp. 223-232

«Lola Massieu. Premio Canarias de Bellas Artes 1990» En Atlántica. Revista de las Artes no 0 octubre 1990 Ed. CAAM, Las Palmas de Gran Canaria 